Alma Mater Studiorum - Università di Bologna DEPARTMENT OF ECONOMICS

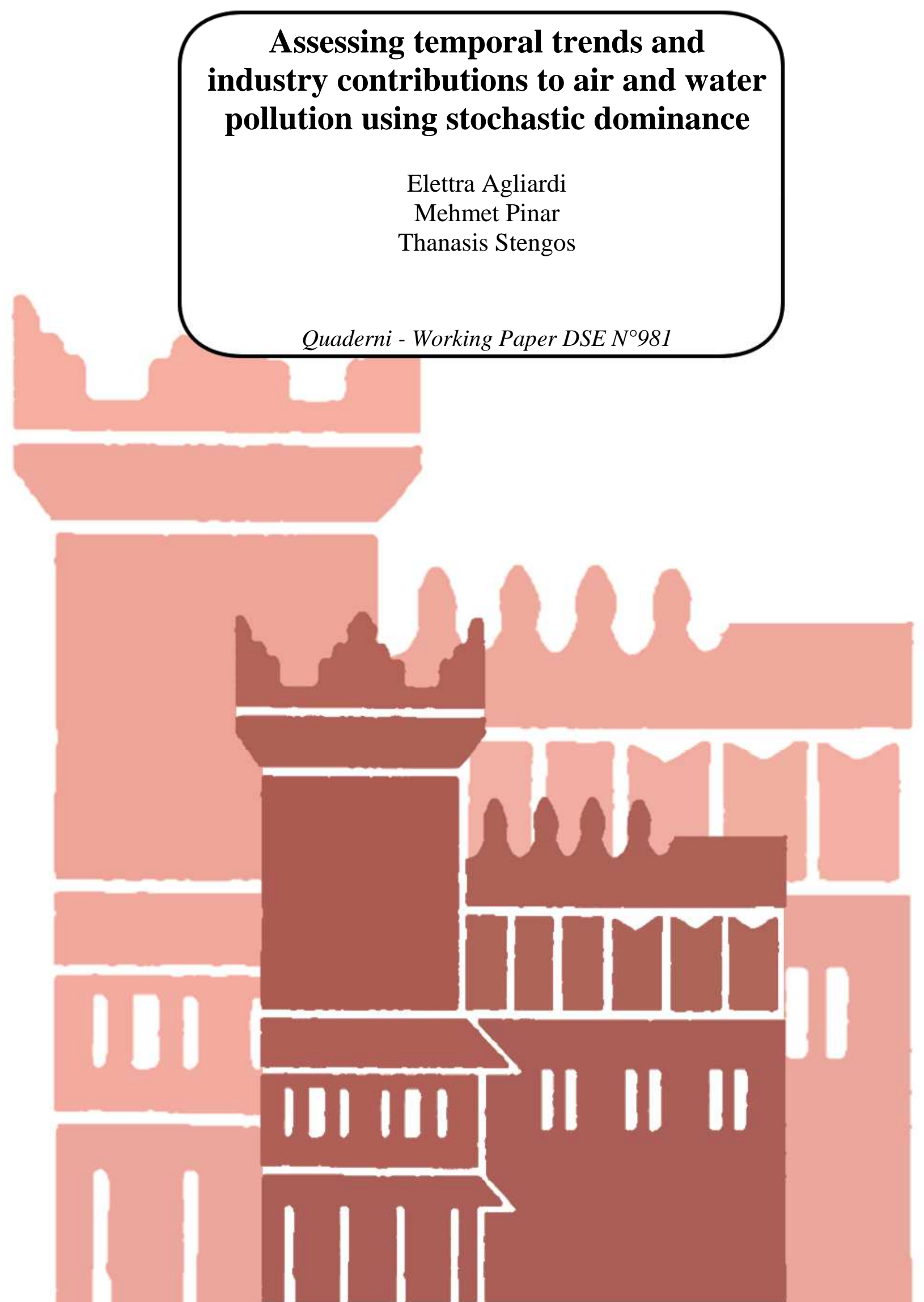




\title{
Assessing temporal trends and industry contributions to air and water pollution using stochastic dominance
}

\author{
Elettra Agliardi \\ CIRI Energia e Ambiente and Department of Economics, University of Bologna* \\ Mehmet Pinar \\ Thanasis Stengos \\ Business School, Edge Hill University ${ }^{\dagger} \quad$ Department of Economics, University of Guelph ${ }^{\ddagger}$
}

December 2, 2014

\begin{abstract}
We employ a stochastic dominance (SD) approach to analyze the components that contribute to environmental degradation over time. The variables that are considered include countries' greenhouse gas (GHG) emissions and water pollution. Our approach is based on pair-wise SD tests. First, we study the dynamic progress of each separate variable over time, from 1990 to 2005, within 5-year horizons. Then, pair-wise SD tests are used to study the major industry contributors to the overall GHG emissions and water pollution at any given time, to uncover the industry which contributes the most to total emissions and water pollution. We find that $\mathrm{CO}_{2}$ emissions not only contribute the most to the GHG emissions over time, but also increased within 15 year in the first-order SD sense. On the other hand, water pollution increased in a second-order SD sense. Pair-wise industry comparisons suggest that the major industry contributors to the $\mathrm{CO}_{2}$ emissions have always been the electricity and heat production sectors, while the transport sector has been the second contributor between 1990 and 2005. Finally, the food industry gradually became the major contributing industry for water pollution over time.
\end{abstract}

JEL Classifications: C4, C5, C14, Q01, Q5, Q51

Keywords: Environmental degradation; Emissions; Water pollution; Stochastic dominance

*Department of Economics, University of Bologna, piazza Scaravilli n.2, I-40126 Bologna, Italy; E-mail: elettra.agliardi@unibo.it

${ }^{\dagger}$ Business School, Edge Hill University, St Helens Road, Ormskirk, Lancashire, L39 4QP, United Kingdom. Tel.: +44 1695657629; fax: +44 1695584675. E-mail:mehmet.pinar@edgehill.ac.uk

‡Department of Economics, University of Guelph, Guelph, Ontario, N1G 2W1, Canada; E-mail: tstengos@uoguelph.ca 


\section{Introduction}

There are already several indicators and assessment methodologies for evaluating in practice the performance of industries, cities and countries, at global, national and regional level, related to economic and environmental sustainability. ${ }^{1}$ One of the recommendations of the Commission on the Measurement of Economic Performance and Social Progress (see Stiglitz et al., 2009) is that the sustainability assessment requires a well-identified dashboard of indicators. The UN Commission on Sustainable Development has derived a list of about fifty indicators, where some of them are based on monetary aggregation methods and others on physical quantities (UN CSD, 2005). Singh et al. (2012) provides a recent overview of a great number of indicators that are already common practice for policy-making.

Some information about various forms of environmental degradation can be obtained by pollution flow accounts. They track the generation of pollution by each industry and final demand sector. By tracking the changes of pollution over time, one can monitor the interaction between the environment and the economy and the progress toward meeting environmental protection goals. Here, we particularly examine air and water pollution that have been extensively analyzed through their linkages to economic development (Meadows et al., 1992; Grove, 1992; Grossman and Krueger, 1992; Dasgupta et al., 2004; Persson et al., 2006; Tamazian et al., 2009 among many others). Air pollution is a major concern for various environmental policies and is perceived as one of the biggest threats to human health and global warming. "The concern with climate change has made tracking greenhouse gas (GHG) emissions a priority" (World Bank, 2010, p.125). As a prime contributor to this process, $\mathrm{CO}_{2}$ has been identified. However, also other gases affect air quality (e.g., methane, nitrous oxide) and need to be taken into account as indicators of air pollution. At the same time, water pollution is another major aspect of environmental degradation and has to be included in the analysis.

In this paper we conduct pair-wise stochastic dominance (SD) comparisons over time for different types of emissions and water pollution to have a full picture of the environmental degradation over time and the major industry contributions to each polluting factor, respectively. Our methodology is particularly well-suited to answer questions like these: Given that GHG emissions or water pollution not only vary over time but also across industries, is there a general increase (decrease) in GHG emissions or water pollution over time? If so, which industry has been the major contributor to those increases (decreases) in GHG emissions or water pollution? For the purpose of distinguishing whether the changes have to be attributed to individual units (countries, industries, etc.) or there has been an overall change affecting all units, we adopt first-order and second-order SD. First-order SD would reveal information whether there has been a point-wise deterioration (improvement) over time. Second-order SD would suggest that there is no deterioration (improvement) for all countries, but an overall deterioration (improvement). In this case, we can analyze the possibility of "free riding" or other externalities in water pollution and overall GHG emissions. Indeed, some countries might have decreased their water pollutions and emissions through free riding and/or trading; however, for other countries' water and air pollution might have worsened because of externalities. As will be specified rigorously later, if there exists a second-order SD in pollution over time, then this means that there has been an overall increase in air and/or water pollution for all given levels, even though not all countries experienced an increase in their pollution levels.

Free-riding and other externalities, which have been studied extensively in the literature, require appropriate

\footnotetext{
${ }^{1}$ See e.g., Dasgupta, 2001; Arrow et al., 2003; Arrow et al., 2004; Millennium Ecosystem Assessment, 2005; World Bank, 2010; Agliardi, 2011; Arrow et al., 2012; Agliardi et al., 2014; Pinar et al., 2014; for detailed discussions of environmental sustainability. See also Blanchet and Fleurbaey (2013) which favor a dimension by dimension dashboard approach in environmental settings.
} 
evaluation. Dominguez-Faus et al. (2009) point out that water pollution increased, due to major transportation biofuel needs. Sigman (2002) analyzes free riding in water quality and finds that free riding may substantially increase pollution in international rivers, whereas there is less free riding within European Union, suggesting that international institutions might work as mitigating factors. However, in a recent study, Bernauer and Kuhn (2010) examine water pollution within Europe and analyze whether democracies that trade and are bound by international treaties are less likely to harm each other environmentally. They find that free-riding incentives are in place. In addition, $\mathrm{CO}_{2}$ emissions have been mainly flowing to other partner countries, through international trade (see e.g., Peters and Hertwich, 2008). For example, China's $\mathrm{CO}_{2}$ emissions have been increasing over time, but it seems to be caused by its exports to other countries. Shui and Harriss (2006) find that around $10 \%$ of China's $\mathrm{CO}_{2}$ emissions are due to its exports to the United States. Similarly, Weber et al. (2008) and Yunfeng and Laike (2010) find that around $20 \%$ of the China's $\mathrm{CO}_{2}$ emissions were due to its exports to other countries. Because of the mechanisms mentioned above, it is crucial to analyze the overall air and water pollution, rather than analyzing individual country improvements or deteriorations alone, something that we achieve in this paper applying second-order SD testing.

Although pair-wise SD comparisons are used extensively in well-being and poverty ${ }^{2}$, only a limited number of studies conducted SD analysis to investigate the environmental degradation over time. To our knowledge, only Makdissi and Wodon (2004) apply SD analysis to compare $\mathrm{CO}_{2}$ emissions between 1985 and 1998, and find that there has been a first-order dominance up to a level, however not for all levels of $\mathrm{CO}_{2}$ emissions. Furthermore, they suggest that the second-order dominance takes into account how much countries over-consume above a threshold and find that there has been an overall increase in emissions over a 13-year period. In this paper, we extend the SD applications to different types of emissions and water pollution and to different polluting industries.

We implement two complementing SD approaches. Firstly, we employ consistent SD tests from Barrett and Donald (2003) to examine the dynamic progress of each separate GHG emissions (i.e., $\mathrm{CO}_{2}$, methane, nitrous and other greenhouse gas emissions) and water pollution over time from 1990 to 2005 within 5-year horizons. In other words, we examine whether there has been a general deterioration or improvement in each component. In that regard we will be able to obtain information on those environmental quality dimensions that are fastmoving (i.e., fast deteriorating or fast improving dimensions) or slow-moving (i.e., dimensions that remain at steady levels) for all countries over the period we analyze. Secondly, pair-wise SD tests allow us to examine the major industry contributors to the GHG emissions and water pollution at any given time. In order words, at a given time, we compare each industry contribution to GHG emissions and water pollution with all possible other industries to uncover the industry which contributes the most to total emissions and water pollution.

One of the important aspects of the Barrett and Donald (2003) approach is that one could compare different sets of countries over time. Therefore, even though a balanced data set may not be available, one could still conduct the SD testing analysis. Secondly, the approach allows for data dependence (time dependence for the over time comparisons, and unit dependence for cross-sectional comparisons) of the water and GHG emissions and as such these comparisons would take into account the time dependence of environmental degradation. Thirdly, comparisons are made for the full empirical distribution of the pollution variables rather than some pre-determined selected parts of the distribution (see Davidson and Duclos, 2000 SD methodology where only selected parts of the distribution are compared which could lead to test inconsistency). Therefore, the results would be robust to the choice of pollution level. Finally, the use of statistical tests allows one to obtain the

\footnotetext{
${ }^{2}$ See, for example, Davidson and Duclos (2000) for income comparison across countries and Pinar et al. (2013) for human development index and its sub-components' evolution over time, among many others.
} 
level of statistical significance of environmental degradation (or improvement) over time. SD analysis therefore provides a robust comparison of environmental degradation over time and the statistical significance level for such degradation.

Our main results are as follows. We find that there has been a general increase in the total fossil-fuel $\mathrm{CO}_{2}$ emissions in the 15-year horizon (between 1990 and 2005) at the 10\% significance level, which has been driven mostly by the increase of the emissions from the combustion of gas fuels (i.e., natural gas) which reflects the global increase in the use of natural gas. On the other hand, there has been neither a general increase nor decrease in the methane and nitrous oxide emissions and their sub-sectors between 1990 and 2005. However, there has been a general increase in the other GHG emissions within 5-year horizons between 1990 and 2000, which has been driven mostly by the general increase in the hydrofluorocarbon (HFC) emissions over that period. Finally, the only emission that registered a general decrease was the perfluorocompound (PFC) emissions from 1990 to 1995. Overall, when different types of GHG emissions are compared, we find a consistent ordering among them over time. Total fossil-fuel $\mathrm{CO}_{2}$ emissions have always been polluting the environment more than methane, nitrous oxide and other GHG emissions between 1990 and 2005. For water pollution and its subindustry contributors, there has not been a general increase between 1995 and 2005. However, we find that total water pollution has increased within 10 years in the second-order sense at the $10 \%$ significance level. In other words, even though there has not been a point-wise increase in water pollution at all levels (i.e., increase in water pollution for all countries), the total sum of water pollution has increased at all pollution levels.

The second set of findings from pair-wise SD applications consists of detailed industry comparisons for emissions and water pollution. Pair-wise $\mathrm{CO}_{2}$ emission comparisons of different sub-industries indicate that the major industry contributor to the $\mathrm{CO}_{2}$ emissions has always been the electricity and heat production sector, while the transport sector has been the second contributor between 1990 and 2005. Furthermore, the liquid fuel (oil) consumption released more $\mathrm{CO}_{2}$ emissions when compared with the gaseous (i.e., natural gas) and solid fuel (i.e., solid fuel material such as coal, wood, and charcoal) consumption over the whole period. For both methane and nitrous oxide emissions, the agricultural sector has always been the major contributor followed by the energy sector from 1990 to 2005. Overall, the major industries contributing to emissions have always been the same for the period between 1990 and 2005. As for water pollution, we find that in 1995 the chemical, textile and food industries were the major contributors dominating the others, such as clay and glass, metal, paper, and wood industries. Yet in 2000, textile and food industries were the major water polluting industries dominating the chemical industry and finally in 2005 , the food industry was the major water polluting industry dominating the rest including textiles and chemicals. Therefore, the way these industries evolve over time with respect to environmental quality offers useful guidelines for the direction of environmental protection and public policy intervention. Fast-moving variables (in the components of GHG emissions and water pollution) stress pollution prevention through redesign of industrial processes and new technologies to reduce pollution. At the same time, they offer directions for policy instruments in the form of official restrictions and positive incentives designed to control activities that may be harmful to the quality of the environment.

The plan of the paper is as follows. Section 2 describes the pair-wise SD methodology from Barrett and Donald (2003), allowing for time dependence, since our analysis covers over time comparisons. Section 3 discusses the data and the empirical results and, finally, Section 4 contains concluding remarks. 


\section{Pair-wise SD tests}

In this section we consider SD pair-wise comparisons of a given variable over two points in time. In particular, we examine the stochastic dominance of the GHG emissions and water pollution in a 15-year and 10-year period, respectively (from 1990 to 2005 for GHG emissions, and from 1995 to 2005 for water pollution) and determine whether there has been a deterioration or improvement in each environmental quality indicator over time. Additionally, SD pair-wise tests are employed for the sub-industry comparisons for GHG emissions and water pollution. In other words, we find major contributing industries to emissions and water pollution at a given time. In this case we have a pair-wise comparison of a given environmental quality indicator over two points in time (or sub-industry contribution at a given time), such as water pollution in year 1995 and in year 2000 (or water pollution from food and chemistry sectors in 1995). Take, for example, water pollution. ${ }^{3}$ In that case, $Z^{1}$ and $Z^{2}$ could be be two environmental variables such as water pollution levels at either two different points in time or different sub-industry contributions to water pollution at a given time for some countries. Let $Z_{k i}$ where $i=1,2, \ldots, N$ and $k=1,2, \ldots, t$ denote the environmental outcome for country, $i$, at a given time period, $k$, which may not be i.i.d. ${ }^{4}$ We define $G(z, F)$ the $c d f$ of the water pollution at point $z$ given by $G(z, F):=\int_{\mathbb{R}} \mathbb{I}\{u \leq z\} d F(u)$, where $z$ is the water pollution level.

Suppose we have (possibly) dependent samples of water pollution levels from two populations (such as water pollution levels of a group of countries at two different points in time or two sub-industry contributions to water pollution levels at a given point in time) that have associated cumulative distribution functions $\left(c d f^{\prime} s\right)$ given by $F_{1}$ and $F_{2}$, and the functions $\mathcal{J}_{j}\left(z, F_{1}\right)$ and $\mathcal{J}_{j}\left(z, F_{2}\right)$. In this context, first-order stochastic dominance (SD1 hereafter) of $F_{1}$ over $F_{2}$ corresponds to $\mathcal{J}_{1}\left(z, F_{1}\right) \leq \mathcal{J}_{1}\left(z, F_{2}\right)$ or $G\left(z, F_{1}\right) \leq G\left(z, F_{2}\right)$ for all $z$, i.e., for all water pollution levels. When this occurs, water pollution levels in the population, summarized by $F_{1}$, is at least as large as that in the $F_{2}$ population, for any utility function $U$ that is a decreasing monotonic function of $z-i . e$, $U^{\prime}(z) \leq 0 .^{5}$

How is this related to water pollution over time? Suppose we have a set of countries. If the $c d f$ of water pollution levels in $1995, F_{2}(z)$, is always at least as large as that of the $c d f$ in $2000, F_{1}(z)$, at any water pollution level, then the proportion of countries below a particular water pollution level for the year 1995 is higher than that of 2000. Therefore, the water pollution levels in 2000 stochastically dominate the corresponding levels in 1995 in the first-order. When the two $c d f$ curves intersect, then the ranking is ambiguous. In this situation we cannot state whether one distribution first-order dominates the other. This leads to an ambiguous situation which makes it necessary to use higher-order SD analysis.

Second-order stochastic dominance (SD2 hereafter) of $F_{1}$ over $F_{2}$ corresponds to $\mathcal{J}_{2}\left(z, F_{1}\right) \leq \mathcal{J}_{2}\left(z, F_{2}\right)$ for all $z$ and the water pollution levels in the population summarized by $F_{1}$ is at least as large as that in the $F_{2}$ population, for any utility function $U$ that is monotonically decreasing and convex, that is, $U^{\prime}(z) \leq 0$ and $U^{\prime \prime}(z) \geq 0$. SD2 is verified, not by comparing the $c d f^{\prime} s$ themselves, but comparing the integrals below them. We examine the area below the $F_{1}(z)$ and $F_{2}(z)$ curves. Given lower and upper boundary levels, we determine the areas beneath the curves and, if the area beneath the $F_{2}(z)$ distribution is larger than the one beneath $F_{1}(z)$ at all levels of $z$, then $F_{1}(z)$ stochastically dominates $F_{2}(z)$ in the second-order sense. Since we look at

\footnotetext{
${ }^{3}$ For simplicity, hereafter we discuss the pair-wise SD tests for water pollution comparisons over time; however, pairwise tests will be applied to over time comparisons for other environmental quality indicators and also to sub-industry comparisons at a given time.

${ }^{4}$ For simplicity, we drop the time and country subscripts throughout the paper.

${ }^{5}$ In social welfare analysis, the utility function is usually an increasing monotonic function. However, in our application, the higher the environmental degradation, the lower the utility is.
} 
the area below the distributions, second-order dominance implies an overall increase in the water pollution and not a point-wise dominance over all the points of the support of one distribution over another. In other words, the sum of total water pollution of the countries that have a water pollution level below a given water pollution level is always larger in one population, when compared with another population. Similarly, SD1 and SD2 could be employed at a given point in time to compare sub-industry contributions to water pollution (or contribution to GHG emissions).

The general hypotheses for testing SD of the a given indicator over time of order $j$ can be written compactly as:

$$
\begin{aligned}
& H_{0}^{j}: \mathcal{J}_{j}\left(z, F_{1}\right) \leq \mathcal{J}_{j}\left(z, F_{2}\right) \text { for all } z \in[0, \bar{z}], \\
& H_{1}^{j}: \mathcal{J}_{j}\left(z, F_{1}\right)>\mathcal{J}_{j}\left(z, F_{2}\right) \text { for some } z \in[0, \bar{z}] .
\end{aligned}
$$

SD of any order of $F_{1}$ over $F_{2}$ implies that $F_{1}$ is no larger than $F_{2}$ at any water pollution level. In this case there is an increase in water pollution levels over time. Thus, if the water pollution levels in 2000 dominate the water pollution levels in 1995 at the first-order sense, then there is an increase in the water pollution level of each country over time. The alternative hypothesis is the converse of the null and implies that there are at least some water pollution levels at which $F_{1}$ (or its integral) is strictly larger than $F_{2}$ (or its integral). In this case, there can be an increase in water pollution levels for some countries and no increase or even a decrease of pollution levels for some other countries over time. Hence, there is no general increase for all countries simultaneously over time.

\subsection{Test Statistics}

We consider two samples from two distributions (e.g., for water pollution levels in 1995 and 2000). The following assumptions are required to allow for different sample sizes:

Assumption 1:

(i) $\left\{X_{i}\right\}_{i=1}^{N}$ and $\left\{Y_{i}\right\}_{i=1}^{M}$ are random samples from distributions with $C D F^{\prime} s F_{1}$ and $F_{2}$, respectively (i.e., water pollution levels at two different points in time);

(ii) the sampling scheme is such that as $N, M \rightarrow \infty, \frac{N}{N+M}=\phi$ where $0<\phi<1$.

Assumption 1(i) deals with the sampling scheme and is satisfied if one has samples of water pollution levels from different segments of a population or separate samples across time. The tests could be implemented both for dependent and independent samples. Assumption 1(ii) implies that the ratio of the sample sizes is finite and bounded away from zero.

The empirical distributions used to construct the tests are, respectively:

$$
\widehat{F}_{1}(z)=\frac{1}{N} \sum_{i=1}^{N} \mathbb{I}\left(X_{i} \leq z\right), \quad \widehat{F}_{2}(z)=\frac{1}{M} \sum_{i=1}^{M} \mathbb{I}\left(Y_{i} \leq z\right) .
$$

The test statistics for testing the hypotheses can be written compactly as follows:

$$
\widehat{S}_{j}=\left(\frac{N M}{N+M}\right)^{1 / 2} \sup _{z}\left(\mathcal{J}_{j}\left(z ; \widehat{F}_{1}\right)-\left(\mathcal{J}_{j}\left(z ; \widehat{F}_{2}\right)\right)\right. \text {. }
$$

Since $\mathcal{J}_{j}$ is a linear operator, then

$$
\mathcal{J}_{j}\left(z ; \widehat{F}_{1}\right)=\frac{1}{N} \sum_{i=1}^{N} \mathcal{J}_{j}\left(z ; \mathbb{I}_{X_{i}}\right)=\frac{1}{N} \sum_{i=1}^{N} \frac{1}{(j-1) !} \mathbb{I}\left(X_{i} \leq z\right)\left(z-X_{i}\right)^{j-1}
$$

where $\mathbb{I}_{X_{i}}$ denotes the indicator function $\mathbb{I}\left(X_{i} \leq x\right)$ (Davidson and Duclos, 2000). 
The asymptotic properties of the tests are given in Barrett and Donald (2003). We consider tests based on the decision rule:

$$
\text { reject } H_{0}^{j} \text { if } \widehat{S}_{j}>c_{j}
$$

where $c_{j}$ is some suitably chosen critical value. In order to make the result operational, we need to find an appropriate critical value $c_{j}$ to satisfy $P\left(\bar{S}_{j}^{F_{2}}>c_{j}\right) \equiv \alpha$ or $P\left(\bar{S}_{j}^{F_{1}, F_{2}}>c_{j}\right) \equiv \alpha$ (some desired probability level such as 0.05 or 0.01 ). Since the distribution of the test statistic depends on the underlying distribution, we rely on bootstrap methods to simulate the p-values (see Barrett and Donald, 2003, for bootstrapping methods). ${ }^{6}$

\section{Empirical Analysis}

\subsection{Data}

The data set used in this paper consists of GHG emissions and water pollution, and their sub-industry contributions for several countries in various years, between 1990 and $2005 .{ }^{7}$ Even though, some types of pollutants have annual data and for longer periods, to keep the analysis the same for all variables, we only consider the periods where all variables have information. GHG emissions consist of total $\mathrm{CO}_{2}$, methane, nitrous oxide and other GHG emissions at a given year for a given country and the latter three emission types are measured in terms of $\mathrm{CO}_{2}$ equivalent levels, which allow us to conduct pair-wise comparisons over time.

The annual national estimates for the total fossil-fuel $\mathrm{CO}_{2}$ emissions and respective fossil-fuel $\mathrm{CO}_{2}$ emissions from solid (coal), liquid (oil) and gas (natural gas) consumption come from Carbon Dioxide Information Analysis Center (CDIAC) of the U.S. Oak Ridge National Laboratory (see Boden et al., 2013). In their work, the total fossil-fuel $\mathrm{CO}_{2}$ emission estimates are obtained by using the energy statistics of the United Nations (2013), following the methodology of Marland and Rotty (1984). ${ }^{8}$ Methane, nitrous oxide and other GHG emissions, and their sub-industry contributions are from International Energy Agency (IEA) obtained from http://www.iea.org/stats/index.asp.

Water pollution is measured by biochemical oxygen demand (BOD) which is the amount of oxygen that bacteria in water will consume in breaking down waste. As the total water pollution is measured for a given country, we use the total BOD levels of countries per day. This data is initially obtained with the methodology of Hettige et al. $(1998,2000)$ where end of pipe discharge of organic emissions are measured using different sector information, and updated by the World Bank's Development Research Group using the same methodology. All the data sets are categorized and taken from the World Bank's World Development Indicators (World Bank, 2012).

In the next section, we present over-time SD comparisons of the different environmental quality dimensions and further we compare different sub-industries to uncover the major contributors to GHG emissions and water pollution.

\footnotetext{
${ }^{6}$ Note that the Barrett and Donald (2003) bootstrapping sampling approach that we use allows for dependent samples. However, we also applied the Linton et al. (2005) sub-sampling approach, which allows for both dependent samples and dependent observations within sample. Both approaches, bootstrapping sampling of the Barrett and Donald (2003) methodology and sub-sampling of the Linton et al. (2005) methodology, yield very similar results. Since the Linton et al (2005) method requires a balanced data set and as such it imposes stricter data requirements we only report the results from the Barrett and Donald (2003) bootstrapping approach.

${ }^{7} \mathrm{CO}_{2}$ emissions consist of annual data from 1990 to 2009, whereas methane, nitrous and other GHG emissions consist of data in 1990, 1995, 2000 and 2005. We have annual data for water pollution from 1986 to 2007.

${ }^{8}$ See http://cdiac.ornl.gov/trends/emis/overview_2010.html for detailed discussion on how foil-fuel $\mathrm{CO}_{2}$ emission estimates are obtained.
} 


\subsection{Pair-wise SD comparisons}

In the next subsections over time pair-wise comparisons of GHG emissions, water pollution, and their subindustry contributions are provided. Furthermore, we conduct SD pair-wise comparisons of GHG emissions to analyze which emission was the major contributor between 1990 and 2005 and which industry contributed mostly to the GHG emissions and water pollution over time.

\subsection{1 $\mathrm{CO}_{2}$ emissions}

First, we present the findings from the pair-wise SD comparisons of $\mathrm{CO}_{2}$ emissions from 1990 to 2005. Table 1 and 2 present the results for SD1 and SD2 over the period under investigation based on bootstrap methods from Barrett and Donald (2003) for SD with dependent data for total, sub-industry and sub-fuel $\mathrm{CO}_{2}$ emissions. We first test whether $\mathrm{CO}_{2}$ emissions in 1995 dominate the $\mathrm{CO}_{2}$ emissions in 1990, and, separately, we test whether $\mathrm{CO}_{2}$ emissions from each individual sector (e.g., emissions from the electricity and heat production in 1995 dominate the emissions from the same sector in 1990). Furthermore, we also test $\mathrm{CO}_{2}$ emissions from each sub-fuel consumption (e.g., whether emissions from natural gas consumption in 1995 dominate its counterpart in 1990). These consecutive tests will allow us to analyze whether over time deteriorations (or improvements) have occurred in $\mathrm{CO}_{2}$ emissions and, in addition, which sector and/or sub-fuel consumption is mainly responsible for such deteriorations (or improvements).

The vertical columns of Tables 1 to 2 represent the years from 1995 to 2005 that are tested for SD against years from 1990 to 2000. Percentage levels in the table represent the significance level of SD (e.g., in Table 1: $\mathrm{CO}_{2}$ emissions in 2005 stochastically dominate the $\mathrm{CO}_{2}$ emissions in 1990 in the first- and second-order sense at the 10 percent level). If there is no conclusive dominance among comparisons, we report them as NA, representing no dominance at that order.

The results from Table 1 suggest that there has been no general increase in total $\mathrm{CO}_{2}$ emissions within a 10 year-period, from 1990 to 2000. In all such cases SD1 is rejected. However, the findings in Table 1 suggest that there has been a general increase in the total $C_{2}$ emissions from 1990 to 2005, since there is a dominance at first-order at the $10 \%$ significant level. Therefore, there has been a clear general degradation in $\mathrm{CO}_{2}$ emissions within 15 years. On the other side, there has been no dominance in each sub-sector (i.e., $\mathrm{CO}_{2}$ emissions from electricity and heat production; manufacturing industries and construction; and other sectors, excluding residential buildings and commercial and public services; residential buildings and commercial and public services; and the transport sector) over the whole period, suggesting that emissions in each sub-sector have been increasing for some countries, and have been decreasing for some others between 1990 and $2005 .{ }^{9}$ Finally, in Table 2 we have the results for $\mathrm{CO}_{2}$ emissions from different sub-fuel consumptions (i.e., gaseous, solid and liquid fuel consumption). We find that there has been a general increase in the $\mathrm{CO}_{2}$ emissions from gaseous fuel consumption within a 15-year period (from 1990 to 2005), since there is a dominance at first-order at the $5 \%$ significance level. Moreover, there has been no dominance over time over the whole period for the $\mathrm{CO}_{2}$ emissions from solid and liquid fuel consumption. Overall, there has been a significant increase in the total $\mathrm{CO}_{2}$ emission from 1990 to 2005 which was mostly driven by the $\mathrm{CO}_{2}$ emissions from the gaseous fuel consumption between the same period. In other words, the general deterioration of $\mathrm{CO}_{2}$ was mainly due to the general increase in $\mathrm{CO}_{2}$ emissions from the gaseous fuel consumption.

\footnotetext{
${ }^{9}$ Given the space limitation, we have not offered the findings in tables when there exists no significant stochastic dominance for the whole section. However, the results are available upon request from the authors.
} 
After analyzing the progress of the $\mathrm{CO}_{2}$ emissions over time, we present the findings from the pair-wise SD comparisons by looking at $\mathrm{CO}_{2}$ emissions from different sub-sectors (i.e., emissions from electricity and heat production; manufacturing industries and construction; and other sectors, excluding residential buildings and commercial and public services; residential buildings and commercial and public services; and the transport sector) in 1990, 1995, 2000 and 2005. We further compare the $\mathrm{CO}_{2}$ emissions from different types of fuel consumption (i.e., gaseous, solid and liquid fuel consumption) in the years 1990, 1995, 2000 and 2005. The panels in Tables 3 and 4 present the results for sub-industry and sub-fuel comparisons, respectively.

Overall, electricity and heat production have been the most dominant sectors over the whole period for $\mathrm{CO}_{2}$ emissions, since emissions in these industries have always been dominating all other sectors at the firstorder sense. The transport sector has been the second contributor to total $\mathrm{CO}_{2}$ emissions, since this sector significantly dominated all other sectors, except the electricity and heat production sector at the first-order sense. The contributions of other sectors to the $\mathrm{CO}_{2}$ emissions are: manufacturing industries and construction; residential buildings and commercial and public services; and other sectors, excluding residential buildings and commercial and public services respectively from the highest to the lowest contributor. ${ }^{10}$ Overall, there has been a clear robust ranking of sectors (from the highest $\mathrm{CO}_{2}$ emitting sector to the lowest one) over the period of 1990-2005.

Finally, Table 4 presents the results of the comparisons between $\mathrm{CO}_{2}$ emissions from different type of fuel consumption from 1990 to 2005 . The results suggest that over the whole period, the liquid fuel consumption has always been the major contributor to the $\mathrm{CO}_{2}$ emissions since $\mathrm{CO}_{2}$ emissions from this type dominate the emissions from the gaseous and solid fuel consumption at a first-order sense at $1 \%$ significance level. On the other hand, $\mathrm{CO}_{2}$ emission from the solid fuel consumption dominate the emission from the gaseous fuel consumption at the second-order sense at $10 \%$ significance level in 1990 and 2005 (i.e., the sum of total $\mathrm{CO}_{2}$ emissions have been higher for the solid fuel consumption than the $\mathrm{CO}_{2}$ emissions from the gaseous fuel consumption but there has been no point-wise increase for all countries) but the relationship between these two types of fuel consumption is ambiguous in 1995 and 2000.

\subsubsection{Methane emissions}

In this section we present the findings from the pair-wise SD applications for the methane emissions from 1990 to 2005. We investigate the evolution of total methane emissions, methane emissions from the agriculture and the energy sector respectively between 1990 and 2005. The findings suggest that there has been no general increase or decrease in total methane emissions over the whole period. Similarly, no general progress of methane emissions from different sub-sectors is found between the same periods.

We also conduct the pair-wise comparisons of methane emissions from the agriculture and energy sectors in 1990, 1995, 2000 and 2005. For the whole period, methane emissions from the agriculture sector have always been higher than methane emission from the energy sector. Table 5 presents the findings for the years 1990 to 2005 with 5-year increments. Methane emissions from the agriculture sector dominate the energy sector at the first-order sense at $1 \%$ significance level. That means that for any given methane emission level, there have been always more countries emitting above that level in agriculture sector than the energy sector. Therefore, there has been a clear robust ranking of sectors (from the highest methane emitting sector to the lowest one) over the period 1990-2005.

\footnotetext{
${ }^{10}$ The significance level of the dominance of each sector on the other one has been different at different periods. We have not gone into a detailed explanation since those results are self-explanatory and we concentrate only on discussing the general patterns.
} 
To help make the interpretation of the SD findings more apparent we added two figures with the cumulative distribution function (CDF) curves of methane emissions over time and of sub-industry comparisons for 2005. Figure 1 presents the cdf plots of methane emissions for 1990, 1995, 2000 and 2005. Clearly, the cdf curves of methane emissions for different years overlap at almost all emission levels and there is no clear dominance at any order. This would suggest that one cannot claim that there is a clear deterioration (or improvement) over time. Figure 2 depicts the cdf's of methane emissions from the agriculture and energy sector in 2005. In this figure, the cdf curve of the methane emissions from the agriculture sector is always below the cdf of the methane emission from the energy sector. This finding suggests a clear first-order SD of emissions from the agriculture sector over the energy sector. In other words, one could suggest a global action plan to reduce methane emissions from the agriculture sector as this is the sector that contributes to methane emissions more than energy at all emission levels.

\subsubsection{Nitrous oxide emissions}

In this section we present the pair-wise SD applications for the nitrous oxide emissions from 1990 to 2005 . We analyze the progress of total nitrous oxide emissions, nitrous oxide emissions from the agriculture, the industrial and the energy sectors respectively between 1990 and 2005. The findings suggest that there has been neither a general increase or decrease in total nitrous oxide emissions nor the nitrous oxide emissions from different sub-sectors.

Similar to the $\mathrm{CO}_{2}$ and methane emissions, we also employ the pair-wise comparisons between three subsectors (i.e., agricultural, industrial and energy sectors) to find the major industry which releases the highest nitrous oxide emissions over time. For the whole period, nitrous oxide emissions from the agriculture sector has always been higher than the other two sectors, while nitrous oxide emissions from the energy sector have always been higher than the industrial sector for the whole period. Table 6 presents the findings for the years 1990 to 2005 with 5-year increments. Nitrous oxide emissions from the agriculture sector dominate the energy and the industrial sectors at the first-order sense at $1 \%$ significance level and, similarly, emissions from the energy sector dominate those of the industrial sector in the first-order sense at a significance level of $1 \%$ over the whole period. In other words, for any given nitrous oxide emission level, there have been always more countries emitting above that level in agriculture sector than the energy and industrial sector. Overall, there has been a clear robust ranking of sectors (from the highest nitrous emitting sector to the lowest one) over the period 1990-2005.

\subsubsection{Other GHG emissions}

Even though the other GHG emissions have always been contributing less to the total, when compared to $\mathrm{CO}_{2}$, methane or nitrous, we apply the same procedure to the former. We conduct pair-wise SD comparisons for the other GHG emissions and its sub-components from 1990 to 2005. The four panels of Table 7 present the results for the evolution of the total other GHG emissions, perfluorocarbon (PFC), hydrofluorocarbon (HFC), and sulfur hexafluoride (SF6) emissions respectively between 1990 and 2005. HFC emissions are mostly due to use of refrigeration, air-conditioning, and insulating foam products (see e.g., Velders et al., 2009). PFC emissions are mainly due to aluminum production (see e.g., Marks et al., 2013), whereas SF6 emissions are due to leakage and venting from the electricity sector, magnesium production, and other minor contributions (see e.g., Olivier et al., 2005).

After conducting our analysis for each type of emission, we find that there has been a general increase in the total GHG emissions in 5-year horizons between 1990 and 2000, yet no clear indication between 2000 and 
2005. On the other hand, HFC emissions have been increasing in 5-year horizons over the whole period as the later 5-year HFC emissions dominate the earlier ones in the first-order sense at the $1 \%$ significance level supporting the fact that increased demand for refrigeration, air-conditioning, and insulating foam products (i.e., main contributors of the HFC emissions). On the other hand, we find no clear result for the SF6 emissions, since SD tests provide no dominance in the period as a whole. More interestingly, we find that there has been a general decrease of the PFC emissions from 1990 to 1995 and from 1990 to 2005. In other words, PFC emissions in 1990 dominate the PFC emissions in 1995 and 2005 in the first-order sense at the 5\% and 1\% significance levels respectively. ${ }^{11}$ Hence, for any given PFC emission level, there have been always less countries emitting above that level in 1990 when compared with 1995 and 2005.

\subsubsection{Comparison between GHG emissions}

Finally, we present the pair-wise SD comparisons between $\mathrm{CO}_{2}$, methane, nitrous oxide and other GHG emissions in 1990, 1995, 2000 and 2005. The four panels of the Table 8 give the results for comparisons between each type of emissions for each respective year. The findings suggest a clear difference between the types of emissions. $\mathrm{CO}_{2}$ has always been the main component that has been releasing emissions when compared with the other type of greenhouse gases. As a result, for any given $\mathrm{CO}_{2}$ equivalent emission level, there have been always more countries emitting $\mathrm{CO}_{2}$ above that level when compared with methane, nitrous oxide and other GHG emissions. Furthermore, methane emissions dominate the nitrous and other GHG emissions between 1990 and 2005 in the first order-sense at the $1 \%$ significance level making it the second major GHG emissions contributor. Similarly, for any given $\mathrm{CO}_{2}$ equivalent emission level, there have always been more countries emitting methane above that level when compared with nitrous oxide and other GHG emissions. Finally, other GHG emissions (i.e., sum of the HFC, PFC and SF6 emissions), have been contributing the least, when compared with the other type of greenhouse gases. This result can help identify policies for achieving improvements in environmental quality. The implication here is that policies aiming to reduce $\mathrm{CO}_{2}$ emissions need to be given priority when compared with the other types of emissions.

\subsection{Water pollution}

For water pollution we have followed a similar approach but the application period now consists only of a 10-year horizon (from 1995 to 2005). ${ }^{12}$ The eight panels of Table 9 give the pair-wise SD test results for the evolution of total water pollution and its sub-industries' contributors over time. The first panel of Table 9 suggests that there was no general increase in water pollution over the whole period. However, there has been an increase in water pollution in the 10-year horizon in a second-order sense, suggesting that total water pollution has increased in this period for some, but not for all countries. Hence the sum of water pollution up to a given pollution level has always been higher in 2005 than in 1995 (i.e., some countries' water pollution decreased, but some others experienced an increase in their water pollution, and the sum of the increases in water pollution has been higher than the sum of the decreases for a given level of pollution). Figure 3 depicts the cdf's of the water pollutant emissions (measured as BOD levels per day) for 1995, 2000 and 2005. As the cdf curves of each year intersect with each other, the tests did not yield any first-order SD. However, when cdf's intersect, one

\footnotetext{
${ }^{11}$ For PFC emissions, years on the vertical axis are tested against the horizontal but the years 1990 to 2000 are tested against the years 1995 and 2005 respectively. Since there has been a decrease over time in PFC emissions, the testing horizon is reversed.

${ }^{12}$ There has been information on water pollution in 1990 for only 12 countries which makes the application impossible before 1995 since the power of tests would not have been reliable.
} 
could test whether there is any clear ordering over time when the integrals of water pollution at each respective year (i.e., sum of the total water pollution up to a water pollution level) are compared. In this case, we find that the water pollutions in 2005 dominates the water pollution in 1995 in the second-order sense at the $10 \%$ significance level. Even though, the cdf's of water pollution in 1995 and 2005 do intersect at some point (i.e., no first-order dominance), one could still discover that the sum of the water pollution up to a level of water pollution is always lower in 2005 than that of 1995 suggesting the presence of second-order SD. In other words, sum of water pollution is always more above a given water pollution level in 2005 than that of 1995.

Similarly to total water pollution, there has been no general improvement or deterioration in sub-industry water pollution over the whole period since there has been no dominance in the first-order sense for all industries. However, water pollution levels from different industries have shown different progress over time. Water pollution from chemical, food and wood industries increased between 1995 and 2000 in the second-order sense. Furthermore, chemical, food, wood, metal, and clay and glass industries increased between 1995 and 2005 in the second-order sense. Finally, no dominance of any order is found for textile and paper and pulp industries. Therefore, one can conclude that the increase in water pollution over time is mostly driven by the chemical, food and wood industries as those industries experienced an overall increase of water pollution in shorter horizons (i.e., an overall increase within 5-year horizons).

Secondly, we analyze the sub-industry contributions to the water pollution in 1995, 2000 and 2005. The three panels of Table 10 present all possible pair-wise comparisons between sub-industry water pollutions in 1995, 2000 and 2005 respectively. In 1995 the chemical industry pollutes water more than the clay and glass, metal and wood industries (i.e., in the first panel of Table 10, chemical industry water pollution stochastically dominates the clay and glass metal and wood industries in the first-order sense at the $10 \%, 5 \%$ and $1 \%$ significance level respectively). Furthermore, water pollution from food and textile industries has been more than pollution from the clay and glass, metal, paper and wood industries at any pollution level in 1995. Finally, in 1995, the clay and glass industry was responsible for water pollution more than the metal industry and paper industry polluted more than the wood industry. Any further comparisons have not suggested any further dominance. Clearly, in 1995, chemical, textile and food industries were the major contributors to water pollution, as at any pollution level there have always been more countries in that industries polluting water than remaining industries above that given pollution level.

In 2000, the majority of the dominance relation between industries remained the same but there were some differences with respect to 1995 . Water pollution from the food industry dominates the pollution from the chemical industry in the first-order sense at the $5 \%$ significance level. In other words, for any pollution level, food industry pollutes water more than chemical industry. Therefore, in 2000, the major contributors to water pollution are the food and textile industries since these industries polluted water above any given pollution level more than any other industry. However, there is no clear SD ordering among food and textile industries when water pollution is considered. Finally, in 2005, water pollution from the food industry contributes more than any other industry (i.e., water pollution from the food industry dominates such pollution from any industry in the first-order sense). Therefore, there is always higher water pollution above any given level from the food industry in comparison with any other industries' pollution. 


\section{Concluding remarks}

In this paper we employ consistent pair-wise SD tests to examine the dynamic progress of GHG emissions (i.e., $\mathrm{CO}_{2}$, methane, nitrous and other GHG emissions) and water pollution over time. We find that there has been a general increase in $\mathrm{CO}_{2}$ emissions in a 15-year horizon at the $10 \%$ significance level (between 1990 and 2005). Also, there has been a general increase in other GHG emissions within 5-year horizons between 1990 and 2000, which has been driven mostly by the general increase in HFC emissions over the same period. The only emissions for which there has been a general decrease are the PFC emissions from 1990 to 1995. Finally, we find a consistent ordering among GHG emissions over time. $\mathrm{CO}_{2}$ emissions have always been polluting the environment more than methane, nitrous oxide and other GHG emissions above any emission level between 1990 and 2005. For water pollution, we find that total water pollution has increased within 10 years in a secondorder sense. We also conduct pair-wise SD tests which allow us to analyze the major industry contributors to the emissions and water pollution at any given time. We find that the major industry contributing to $\mathrm{CO}_{2}$ emissions has always been the electricity and heat production sectors, followed by the transport sector between 1990 and 2005. For both methane and nitrous oxide emissions, the agricultural sector has always been the major contributor, followed by the energy sector from 1990 to 2005.

The pair-wise SD results can provide useful information to policy makers in their efforts to design policies that compare the risks from environmental degradation. Overall, our results help policy makers to identify policies for achieving improvements in environmental quality. In other words, policies aiming at reducing $\mathrm{CO}_{2}$ emissions need to be given priority, when compared with the other types of emissions. In order to achieve lower levels of $\mathrm{CO}_{2}$ emissions, special attention has to be given to those industrial sectors which are mainly responsible for these emissions, namely electricity and heat production and the transport sector. In that case, there are alternative options available to policy makers to reduce emissions. For example, Palmer and Burtraw (2005) discuss for the United States policies such as the renewables portfolio standard (RPS) for a given state. It requires that a minimum percentage of the electricity produced or sold in the state must come from renewable sources. Their analysis suggests that the RPS policy seems to be the best method for promoting renewable sources of energy and appears to be reasonably effective at achieving direct reductions in carbon emissions (for a recent renewable energy policy recommendations for the United States and the European Union, see Schmalensee, 2012). Furthermore, as the second major industry that contributes to $\mathrm{CO}_{2}$ emissions is the transport sector, a tax on gasoline will eventually decrease carbon emissions. To that effect, in a recent application, Davis and Kilian (2011) find that a ten-cent per gallon increase in the gasoline tax would reduce vehicle carbon emissions in the United States by about $1.5 \%$ and therefore reduce overall carbon emissions by approximately $0.5 \%$. Finally, Yan and Crookes (2009) analyze the transport sector's impact on emissions in China and project the future impact of different alternative policies, such as private vehicle control, fuel economy regulation and, fuel tax and biofuel promotion. They find that such policies would have decreased emissions by $40 \%$ when compared to the case where no actions were taken.

For the case of water pollution, we find that not only there has been an increase in water pollution within 10 year in the second-order sense, but also we find that the food and chemical industries are the major drivers, as both water pollution from those industries increased in a second-order sense over time in a 5-year horizon. In addition, we find that the chemical, textile and food industries were the major contributors in 1995 whereas in 2000, textile and food industries were the major water polluting industries. Finally, in 2005, the food industry has become the major water polluting industry, as water pollution from this industry dominated pollutions from any other industry. In other words, those industries listed above have been degrading the environment more 
than any industry for any given degradation level. Therefore, there has been a clear ordering of industries which were the main responsible for overall water pollution over time.

As the agriculture sector is the major contributor to the methane emissions over the whole period and the food sector is becoming the industry that is polluting water the most, our findings suggest the interlinkages between air and water pollution. Dominguez-Faus et al. (2009) point out that water pollution "will likely be intensified by the increasing demand for biomass-derived fuels (i.e. biofuels) for transportation biofuel needs, because large quantities of water are needed to grow the fuel crops, and water pollution is exacerbated by agricultural drainage containing fertilizers, pesticides, and sediment" (Dominguez-Faus et al., 2009, p. 3005). Therefore, our findings support what has been suggested by Dominguez-Faus et al. (2009), as the methane emissions from agriculture have been the dominant ones and the food sector is becoming the major water polluting industry. Given the world-wide deterioration in both dimensions, increasing charges for irrigation water for biofuel crops are suggested. Potentially, there have been major spillovers in environmental degradation across countries and across water and emission pollution. It is therefore necessary to have a global collective action to reduce air and water pollution. In the direction of a global action, Ostrom (2010) suggests that it is necessary to have an external authority that determines the actions to be taken and encourages polycentric efforts to reduce the risks associated with the emissions of greenhouse gases. Although Olmstead (2010) provides directions to cope with water pollution at regional, national and international level, she claims that water pollution in transboundary settings is still a challenge. However, we should point out that this paper analyses the temporal trends of air and water pollution independently from each other. As pointed out above, one might expect that air and water pollution are interdependent. For example, the interdependence between food and energy production will have an impact on the environment, through emissions and water pollution (see e.g., Tilman et al. 2009). Even though, it would not be straightforward to identify the dependence levels of the different polluting factors, a future analysis which could tackle this problem would constitute a promising future research agenda.

Another interesting extension for future research is to employ recently developed SD tests in conditional setting to analyze environmental degradation (see e.g., Delgado and Escanciano, 2013; Gonzalo and Olmo, 2014). One could employ conditional SD analysis to analyze pollution trends given the income (consumption) level of countries controlling for important other factors that are responsible for pollution while testing the pollution levels over-time.

\section{References}

Agliardi, E., 2011. Sustainability in uncertain economies. Environ. Resour. Econ. 48, 71-82.

Agliardi, E., Pinar, M., Stengos, T., 2014. An environmental degradation index based on stochastic dominance. Emp. Econ., http://dx.doi.org/10.1007/s00181-014-0853-3.

Arrow, K.J., Dasgupta, P.S., Mäler, K.-G., 2003. Evaluating projects and assessing sustainable development in imperfect economies. Environ. Resour. Econ. 26, 647-685.

Arrow, K.J., Dasgupta, P.S., Goulder, L.H., Daily, G., Ehrlich, P.R., Heal, G.M., Levin, S., Mäler, K.-G., Schneider, S., Starett, D.A., Walker, B., 2004. Are we consuming too much? J. Econ. Perspect. 18, 147-172.

Arrow, K.J., Dasgupta, P.S., Goulder, L.H., Mumford, K.J., Oleson, K., 2012. Sustainability and the measurement of wealth. Environ. Dev. Econ. 17, 317-353.

Barrett, G.F., Donald, S.G., 2003. Consistent tests for stochastic dominance. Econometrica 71, 71-104.

Bernauer. T., Kuhn, P.M., 2010. Is there an environmental version of the Kantian peace? Insights from 
water pollution in Europe. Eur. J. Int. Relat. 16, 77-102.

Blanchet, D., Fleurbaey, M., 2013. Beyond GDP: measuring welfare and assessing sustainability. Oxford University Press, New York.

Boden, T.A., Marland, G., Andres, R.J., 2013. Global, regional, and national fossil-fuel $\mathrm{CO}_{2}$ emissions. Carbon Dioxide Information Analysis Center, Oak Ridge National Laboratory, U.S. Department of Energy, Oak Ridge, TN, USA. http://dx.doi.org/10.3334/CDIAC/00001_V2013

Dasgupta, P.S., 2001. Human well-being and the natural environment. Oxford University Press, Oxford.

Dasgupta, P.S., Hong, J.H., Laplante, B., Mamingi, N., 2004. Disclosure of environmental violations and stock market in the Republic of Korea. Ecol. Econ. 58, 759-777.

Davidson, R., Duclos, J.-Y., 2000. Statistical inference for stochastic dominance and for the measurement of poverty and inequality. Econometrica 68, 1435-1464.

Delgado, M.A., Escanciano, J.C., 2013. Conditional stochastic dominance testing. J. Bus. Econ. Stat. 31 (1), 16-28.

Dominguez-Faus, R., Powers, S.E., Burken, J.G., Alvarez, P.J., 2009. The water footprint of biofuels: a drink or drive issue? Envir. Sci. Tech. 43, 3005-3010.

Gonzalo, J., Olmo, J., 2014. Conditional stochastic dominance tests in dynamic settings. Int. Econ. Rev. $55(3), 819-838$.

Grossman, G., Krueger, A., 1992. Environmental impacts of a North American free trade agreement. CEPR Discussion Paper no. 644.

Grove, R.H., 1992. Origins of western environmentalism. Sci. Am. 267, 42-47.

Hettige, H., Mani, M., Wheeler, D., 1998. Industrial pollution in economic development: Kuznets revisited. Policy Research Working Paper WPS 1876. The World Bank, Washington.

Hettige, H., Mani, M., Wheeler, D., 2000. Industrial pollution in economic development: Kuznets revisited. J. Dev. Econ. 62, 445-476.

Linton, O., Maasoumi, E., Wang, Y.-J., 2005. Consistent testing for stochastic dominance under general sampling schemes. Rev. Econ. Stud. 72, 735-765.

Marland, G., Rotty, R.M., 1984. Carbon dioxide emissions from fossil fuels: A procedure for estimation and results for 1950-82. Tellus 36(B), 232-361.

Makdissi, P., Wodon, Q., 2004. Robust comparisons of natural resource depletion indices. Econ. Bull. 9, $1-9$.

Marks, J., Tabereaux, A., Pape, D., Bakshi, V., Dolin, E.J., 2013. Factors affecting PFC emissions from commercial aluminum reduction cells, in: Bearne, G., Dupuis, M., Tarcy, G. (Eds.), Essential Readings in Light Metals: Aluminum Reduction Technology, Volume 2. John Wiley \& Sons Inc., Hoboken, NJ, USA. http://dx.doi.org/10.1002/9781118647851.ch151

Meadows, D.H., Meadows, D.L., Randers, J., Behrens, W. 1992. The limits to growth. Universe Books, New York.

Millennium Ecosystem Assessment, 2005. Ecosystems and human well-being: synthesis. World Resources Institute, Washington.

Olivier, J.G.J., Van Aardenne, J.A., Dentener, F., Ganzeveld, L., Peters, J.A.H.W., 2005. Recent trends in global greenhouse gas emissions: regional trends and spatial distribution of key sources, In: van Amstel (Ed.), Non-CO2 Greenhouse Gases (NCGG-4). Millpress, Rotterdam, pp. 325-330. 
Ostrom, E., 2010. Polycentric systems for coping with collective action and global environmental change. Global Environ. Chang. 20, 550-557.

Olmstead, S.M., 2010. The economics of water quality. Rev. Environ. Econ. Policy 4, 44-62.

Palmer, K., Burtraw, D., 2005. Cost-effectiveness of renewable electricity policies. Energy Econ. 27, 873-894.

Persson, T.A., Azar, C., Lindgren, K., 2006. Allocation of $\mathrm{CO}_{2}$ emission permits-economic incentives for emission reductions in developing countries. Energy Policy 34, 1889-1899.

Peters, G.P., Hertwich, E.G., 2008. $\mathrm{CO}_{2}$ embodied in international trade with implications for global climate policy. Envir. Sci. Tech. 42, 1401-1407.

Pinar, M., Stengos, T., Topaloglou, N., 2013. Measuring human development: a stochastic dominance approach. J. Econ. Growth 18, 69-108.

Pinar, M., Cruciani, C., Giove, S., Sostero, M., 2014. Constructing the FEEM sustainability index: A Choquet integral application. Ecol. Indic. 39, 189-202.

Schmalensee, R., 2012. Evaluating policies to increase electricity generation from renewable energy. Rev. Environ. Econ. Policy 6, 45-64.

Shui, B., Harriss, R.C., 2006. The role of $\mathrm{CO}_{2}$ embodiment in US-China trade. Energy Policy 34, 4063-4069.

Sigman, H., 2002. International spillovers and water quality in rivers: do countries free ride? Am. Econ. Rev. 92, 1152-1159.

Singh, R.K., Murty, H.R., Gupta, S.K., Dikshit, A.K., 2012. An overview of sustainability assessment methodologies. Ecol. Indic. 15, 281-299.

Stiglitz, J.E., Sen, A., Fitoussi, J.-P., 2009. Report by the commission on the measurement of economic performance and social progress. http://www.stiglitz-sen-fitoussi.fr/documents/rapport_anglais.pdf.

Tamazian, A., Chousa, J.P., Vadlamannati, K.C., 2009. Does higher economic and financial development lead to environmental degradation: evidence from BRIC countries. Energy Policy 37, 246-253.

Tilman, D., Socolow, R., Foley, J.A., Hill, J., Larson, E., Lynd, L., Pacala, S., Reilly, J., Seachinger, T., Somerville, C., Williams, R., 2009. Beneficial Biofuels-The food, energy, and environment trilemma. Science $325,270-271$.

United Nations, 2013. 2009 Energy Statistics Yearbook. United Nations Department for Economic and Social Information and Policy Analysis, Statistics Division, New York.

UN CSD, 2005. Indicators of sustainable development. CSD theme indicator framework. UN Commission on Sustainable Development, New York.

Velders, G.J.M., Fahey, D.W., Daniel, J.S., McFarland, M., Andersen, S.O., 2009. The large contribution of projected HFC emissions to future climate forcing. Proc. Natl. Acad. Sci. USA 106 (27), 10949-10954.

Weber, C.L., Peters, G.P., Guan, D., Hubacek, K., 2008. The contribution of Chinese exports to climate change. Energy Policy 36, 3572-3577.

World Bank, 2010. The changing wealth of nations: measuring sustainable development in the new millennium. The World Bank, Washington.

World Bank, 2012. World Development Indicators 2012. World Bank, Washington.

Yan, X., Crookes, R.J., 2009. Reduction potentials of energy demand and GHG emissions in China's road transport sector. Energy Policy 37, 658-668.

Yunfeng, Y., Laike, Y., 2010. China's foreign trade and climate change: A case study of $\mathrm{CO}_{2}$ emissions. Energy Policy 38, 350-356. 


\section{Table 1}

Pair-wise SD comparisons of total and sub-industry $\mathrm{CO}_{2}$ emissions over time. Total $\mathrm{CO}_{2}$ emissions

\begin{tabular}{lllcc}
\hline \multirow{2}{*}{1995} & & 1990 & 1995 & 2000 \\
& SD1 & NA & - & - \\
& SD2 & NA & - & - \\
2000 & SD1 & NA & NA & - \\
& SD2 & NA & NA & - \\
& SD1 & $10 \%$ & NA & NA \\
& SD2 & $10 \%$ & NA & NA \\
\hline
\end{tabular}

The vertical columns represent the years 1995 to 2005 that are tested for stochastic dominance against years from 1990 to 2000. Percentage levels in the table represent the significance level of stochastic dominance. NA represents that there is no dominance at that order.

\section{Table 2}

Pair-wise SD comparisons of sub-fuel $\mathrm{CO}_{2}$ emissions over time.

$\mathrm{CO}_{2}$ emissions from gaseous fuel consumption

\begin{tabular}{lllcc}
\multirow{2}{*}{1995} & & 1990 & 1995 & 2000 \\
& SD1 & NA & - & - \\
& SD2 & NA & - & - \\
2005 & SD1 & NA & NA & - \\
& SD2 & NA & NA & - \\
& SD1 & $5 \%$ & NA & NA \\
& SD2 & $5 \%$ & NA & NA \\
\hline
\end{tabular}

The vertical columns represent the years 1995 to 2005 that are tested for stochastic dominance against years from 1990 to 2000. Percentage levels in the table represent the significance level of stochastic dominance. NA represents that there is no dominance at that order. 
Table 3

Pair-wise SD comparisons of $\mathrm{CO}_{2}$ emissions from industries.

\begin{tabular}{|c|c|c|c|c|c|c|c|}
\hline \multicolumn{4}{|c|}{ a) Sub-industry comparisons in 1990} & \multicolumn{4}{|c|}{ b) Sub-industry comparisons in 1995} \\
\hline $\begin{array}{l}\text { Industry } \\
\text { comparisons }\end{array}$ & $\begin{array}{c}\text { Dominance } \\
\text { Outcome }\end{array}$ & SD1 & SD2 & $\begin{array}{l}\text { Industry } \\
\text { comparisons }\end{array}$ & $\begin{array}{c}\text { Dominance } \\
\text { Outcome }\end{array}$ & SD1 & SD2 \\
\hline EH versus MC & EH dominates MC & $5 \%$ & $5 \%$ & EH versus MC & EH dominates MC & $5 \%$ & $5 \%$ \\
\hline EH versus OT & EH dominates OT & $1 \%$ & $1 \%$ & EH versus OT & EH dominates OT & $1 \%$ & $1 \%$ \\
\hline EH versus $\mathrm{RC}$ & $\mathrm{EH}$ dominates RC & $1 \%$ & $1 \%$ & EH versus RC & EH dominates RC & $1 \%$ & $1 \%$ \\
\hline EH versus TR & EH dominates TR & $5 \%$ & $5 \%$ & EH versus TR & EH dominates TR & $5 \%$ & $5 \%$ \\
\hline MC versus OT & MC dominates OT & $1 \%$ & $1 \%$ & MC versus OT & MC dominates OT & $1 \%$ & $1 \%$ \\
\hline MC versus $\mathrm{RC}$ & MC dominates RC & $1 \%$ & $1 \%$ & MC versus $\mathrm{RC}$ & MC dominates RC & $1 \%$ & $1 \%$ \\
\hline MC versus TR & TR dominates MC & $10 \%$ & $10 \%$ & MC versus TR & TR dominates MC & $5 \%$ & $5 \%$ \\
\hline OT versus $\mathrm{RC}$ & $\mathrm{RC}$ dominates OT & $1 \%$ & $1 \%$ & OT versus RC & $\mathrm{RC}$ dominates OT & $1 \%$ & $1 \%$ \\
\hline OT versus TR & TR dominates OT & $1 \%$ & $1 \%$ & OT versus TR & TR dominates OT & $1 \%$ & $1 \%$ \\
\hline $\mathrm{RC}$ versus TR & TR dominates RC & $1 \%$ & $1 \%$ & $\mathrm{RC}$ versus TR & TR dominates RC & $1 \%$ & $1 \%$ \\
\hline \multicolumn{4}{|c|}{ c) Sub-industry comparisons in 2000} & \multicolumn{4}{|c|}{ d) Sub-industry comparisons in 2005} \\
\hline $\begin{array}{l}\text { Industry } \\
\text { comparisons }\end{array}$ & $\begin{array}{c}\text { Dominance } \\
\text { Outcome }\end{array}$ & SD1 & SD2 & $\begin{array}{l}\text { Industry } \\
\text { comparisons }\end{array}$ & $\begin{array}{c}\text { Dominance } \\
\text { Outcome }\end{array}$ & SD1 & SD2 \\
\hline $\mathrm{EH}$ versus $\mathrm{MC}$ & EH dominates MC & $5 \%$ & $5 \%$ & EH versus MC & EH dominates MC & $1 \%$ & $1 \%$ \\
\hline EH versus OT & EH dominates OT & $1 \%$ & $1 \%$ & $\mathrm{EH}$ versus OT & EH dominates OT & $1 \%$ & $1 \%$ \\
\hline EH versus RC & EH dominates RC & $1 \%$ & $1 \%$ & EH versus RC & EH dominates RC & $1 \%$ & $1 \%$ \\
\hline EH versus TR & EH dominates TR & $10 \%$ & $10 \%$ & EH versus TR & EH dominates TR & $5 \%$ & $5 \%$ \\
\hline MC versus OT & MC dominates OT & $1 \%$ & $1 \%$ & MC versus OT & MC dominates OT & $1 \%$ & $1 \%$ \\
\hline MC versus RC & MC dominates RC & $1 \%$ & $1 \%$ & MC versus RC & MC dominates RC & $1 \%$ & $1 \%$ \\
\hline MC versus TR & TR dominates MC & $5 \%$ & $5 \%$ & MC versus TR & TR dominates MC & $5 \%$ & $5 \%$ \\
\hline OT versus RC & RC dominates OT & $1 \%$ & $1 \%$ & OT versus RC & $\mathrm{RC}$ dominates OT & $1 \%$ & $1 \%$ \\
\hline OT versus TR & TR dominates OT & $1 \%$ & $1 \%$ & OT versus TR & TR dominates OT & $1 \%$ & $1 \%$ \\
\hline $\mathrm{RC}$ versus TR & TR dominates RC & $1 \%$ & $1 \%$ & $\mathrm{RC}$ versus TR & TR dominates RC & $1 \%$ & $1 \%$ \\
\hline
\end{tabular}

EH represents the emissions from "electricity and heat production"; MC represents the emissions from "manufacturing industries and construction"; OT represents the emissions from "other sectors, excluding residential buildings and commercial and public services"; RC represents the emissions from "residential buildings and commercial and public services"; TR represents the emissions from "transport sector". Industry comparison columns represent the all possible sub-industry comparisons at a given year. Dominance outcome column offers the outcome when emissions from different sub-industries are compared. SD1 and SD2 represent the significance levels for the first- and second-order dominance. 
Table 4

Pair-wise SD comparisons of $\mathrm{CO}_{2}$ emissions from sub-fuel consumption. a) Sub-fuel comparisons in 1990

\begin{tabular}{lccc}
\hline Industry comparisons & Dominance Outcome & SD1 & SD2 \\
\hline GAS versus LIQUID & LIQUID dominates & $1 \%$ & $1 \%$ \\
GAS versus SOLID & SOLID dominates & NA & $10 \%$ \\
LIQUID versus SOLID & LIQUID dominates & $1 \%$ & $1 \%$
\end{tabular}

b) Sub-fuel comparisons in 1995

\begin{tabular}{lccc}
\hline Industry comparisons & Dominance Outcome & SD1 & SD2 \\
\hline GAS versus LIQUID & LIQUID dominates & $1 \%$ & $1 \%$ \\
GAS versus SOLID & NA & NA & NA \\
LIQUID versus SOLID & LIQUID dominates & $1 \%$ & $1 \%$
\end{tabular}

c) Sub-fuel comparisons in 2000

\begin{tabular}{lccc}
\hline Industry comparisons & Dominance Outcome & SD1 & SD2 \\
\hline GAS versus LIQUID & LIQUID dominates & $1 \%$ & $1 \%$ \\
GAS versus SOLID & NA & NA & NA \\
LIQUID versus SOLID & LIQUID dominates & $1 \%$ & $1 \%$
\end{tabular}

d) Sub-fuel comparisons in 2005

\begin{tabular}{lccc}
\hline Industry comparisons & Dominance Outcome & SD1 & SD2 \\
\hline GAS versus LIQUID & LIQUID dominates & $1 \%$ & $1 \%$ \\
GAS versus SOLID & SOLID dominates & NA & $10 \%$ \\
LIQUID versus SOLID & LIQUID dominates & $1 \%$ & $1 \%$ \\
\hline
\end{tabular}

GAS represents the emissions from "gaseous fuel consumption"; LIQUID represents the emissions from "liquid fuel consumption"; SOLID represents the emissions from "solid fuel consumption". Industry comparison columns represent the all possible sub-industry comparisons at a given year. Dominance outcome column offers the outcome when emissions from different sub-fuels are compared. SD1 and SD2 represent the significance levels for the first- and second-order dominance. NA represents that there is no dominance at that order. 
Table 5

Pair-wise SD comparisons of methane emissions from sectors.

\begin{tabular}{lccc}
\hline \multicolumn{2}{l}{ a) Sub-sector comparisons in 1990} & & \\
\hline Industry comparisons & Dominance Outcome & SD1 & SD2 \\
\hline $\begin{array}{l}\text { AGRI versus ENER } \\
\text { b) Sub-sector comparisons in }\end{array}$ & AGRI dominates & $1 \%$ & $1 \%$ \\
\hline Industry comparisons & Dominance Outcome & SD1 & SD2 \\
\hline $\begin{array}{l}\text { AGRI versus ENER } \\
\text { c) Sub-sector comparisons in }\end{array}$ & AGRI dominates & $1 \%$ & $1 \%$ \\
\hline Industry comparisons & Dominance Outcome & SD1 & SD2 \\
\hline $\begin{array}{l}\text { AGRI versus ENER } \\
\text { d) Sub-sector comparisons in }\end{array}$ & AGRI dominates & $1 \%$ & $1 \%$ \\
\hline Industry comparisons & Dominance Outcome & SD1 & SD2 \\
\hline AGRI versus ENER & AGRI dominates & $1 \%$ & $1 \%$ \\
\hline
\end{tabular}

AGRI represents the methane emissions from "agricultural sector"; ENER represents the methane emissions from "energy sector". First column represents the all possible subindustry comparisons at a given year. Second column present the dominance outcome when emissions from different sub-industries are compared. SD1 and SD2 represent the significance levels for the first- and second-order dominance.

Table 6

Pair-wise SD comparisons of nitrous oxide emissions from sectors.

\begin{tabular}{lccc}
\hline a) Sub-sector comparisons in 1990 & & \\
\hline Industry comparisons & Dominance Outcome & SD1 & SD2 \\
\hline AGRI versus ENER & AGRI dominates & $1 \%$ & $1 \%$ \\
AGRI versus INDUS & AGRI dominates & $1 \%$ & $1 \%$ \\
ENER versus INDUS & ENER dominates & $1 \%$ & $1 \%$
\end{tabular}

b) Sub-sector comparisons in 1995

\begin{tabular}{lccc}
\hline Industry comparisons & Dominance Outcome & SD1 & SD2 \\
\hline AGRI versus ENER & AGRI dominates & $1 \%$ & $1 \%$ \\
AGRI versus INDUS & AGRI dominates & $1 \%$ & $1 \%$ \\
ENER versus INDUS & ENER dominates & $1 \%$ & $1 \%$
\end{tabular}

c) Sub-sector comparisons in 2000

\begin{tabular}{lccc}
\hline Industry comparisons & Dominance Outcome & SD1 & SD2 \\
\hline AGRI versus ENER & AGRI dominates & $1 \%$ & $1 \%$ \\
AGRI versus INDUS & AGRI dominates & $1 \%$ & $1 \%$ \\
ENER versus INDUS & ENER dominates & $1 \%$ & $1 \%$
\end{tabular}

d) Sub-sector comparisons in 2005

\begin{tabular}{lccc}
\hline Industry comparisons & Dominance Outcome & SD1 & SD2 \\
\hline AGRI versus ENER & AGRI dominates & $1 \%$ & $1 \%$ \\
AGRI versus INDUS & AGRI dominates & $1 \%$ & $1 \%$ \\
ENER versus INDUS & ENER dominates & $1 \%$ & $1 \%$
\end{tabular}

AGRI represents the nitrous oxide emissions from "agricultural sector"; ENER represents the nitrous oxide emissions from "energy sector"; INDUS represents the nitrous oxide emissions from "industrial sector". First column represents the all possible sub-industry comparisons at a given year. Second column present the dominance outcome when emissions from different sub-industries are compared. SD1 and SD2 represent the significance levels for the first- and second-order dominance. 
Table 7

Pair-wise SD comparisons other GHG, HFC, PFC and SF6 emissions over time.

\begin{tabular}{|c|c|c|c|c|c|c|c|c|c|}
\hline \multicolumn{5}{|c|}{ a) Total other GHG emissions } & \multicolumn{5}{|c|}{ b) HFC emissions } \\
\hline & & 1990 & 1995 & 2000 & & & 1990 & 1995 & 2000 \\
\hline \multirow[t]{2}{*}{1995} & SD1 & $1 \%$ & - & - & 1995 & SD1 & $1 \%$ & - & - \\
\hline & SD2 & $1 \%$ & - & - & & SD2 & $1 \%$ & - & - \\
\hline \multirow[t]{2}{*}{2000} & SD1 & $1 \%$ & $5 \%$ & - & 2000 & SD1 & $1 \%$ & $1 \%$ & - \\
\hline & SD2 & $1 \%$ & $5 \%$ & - & & SD2 & $1 \%$ & $1 \%$ & - \\
\hline \multirow[t]{2}{*}{2005} & SD1 & $1 \%$ & $1 \%$ & NA & 2005 & SD1 & $1 \%$ & $1 \%$ & $1 \%$ \\
\hline & SD2 & $1 \%$ & $1 \%$ & NA & & SD2 & $1 \%$ & $1 \%$ & $1 \%$ \\
\hline \multicolumn{5}{|c|}{ c) PFC emissions } & \multicolumn{5}{|c|}{ d) SF6 emissions } \\
\hline & & 1995 & 2000 & 2005 & & & 1990 & 1995 & 2000 \\
\hline \multirow[t]{2}{*}{1990} & SD1 & $5 \%$ & NA & $1 \%$ & 1995 & SD1 & NA & - & - \\
\hline & SD2 & $5 \%$ & NA & $1 \%$ & & SD2 & NA & - & - \\
\hline \multirow[t]{2}{*}{1995} & SD1 & - & NA & NA & 2000 & SD1 & NA & NA & - \\
\hline & SD2 & - & NA & NA & & SD2 & NA & NA & - \\
\hline \multirow[t]{2}{*}{2000} & SD1 & - & - & NA & 2005 & SD1 & NA & NA & NA \\
\hline & SD2 & - & - & NA & & SD2 & NA & NA & NA \\
\hline
\end{tabular}

The vertical columns represent the years 1995 to 2005 that are tested for stochastic dominance against years from 1990 to 2000. Percentage levels in the table represent the significance level of stochastic dominance. The vertical and horizontal axes are reversed for PFC emissions to represent the improvement over time. NA represents that there is no dominance at that order. 
Table 8

Pair-wise comparison of $\mathrm{CO}_{2}$, methane, nitrous oxide and other $\mathrm{GHG}$ emissions.

\begin{tabular}{llcc}
\hline a) Emission comparisons in 1990 & & \\
\hline Industry comparisons & Dominance Outcome & SD1 & SD2 \\
\hline $\mathrm{CO}_{2}$ versus MET & $\mathrm{CO}_{2}$ dominates & $5 \%$ & $5 \%$ \\
$\mathrm{CO}_{2}$ versus NIT & $\mathrm{CO}_{2}$ dominates & $1 \%$ & $1 \%$ \\
$\mathrm{CO}_{2}$ versus OTH & $\mathrm{CO}_{2}$ dominates & $1 \%$ & $1 \%$ \\
$\mathrm{MET}$ versus NIT & Methane dominates & $1 \%$ & $1 \%$ \\
MET versus OTH & Methane dominates & $1 \%$ & $1 \%$ \\
NIT versus OTH & Nitrous oxide dominates & $1 \%$ & $1 \%$
\end{tabular}

b) Emission comparisons in 1995

\begin{tabular}{lccc}
\hline Industry comparisons & Dominance Outcome & $\mathrm{SD} 1$ & $\mathrm{SD} 2$ \\
\hline $\mathrm{CO}_{2}$ versus MET & $\mathrm{CO}_{2}$ dominates & $1 \%$ & $1 \%$ \\
$\mathrm{CO}_{2}$ versus NIT & $\mathrm{CO}_{2}$ dominates & $1 \%$ & $1 \%$ \\
$\mathrm{CO}_{2}$ versus OTH & $\mathrm{CO}_{2}$ dominates & $1 \%$ & $1 \%$ \\
$\mathrm{MET}$ versus NIT & Methane dominates & $1 \%$ & $1 \%$ \\
MET versus OTH & Methane dominates & $1 \%$ & $1 \%$ \\
NIT versus OTH & Nitrous oxide dominates & $1 \%$ & $1 \%$
\end{tabular}

c) Emission comparisons in 2000

\begin{tabular}{|c|c|c|c|c|c|c|c|}
\hline & \\
\hline Industry comparisons & Dominance Outcome & SD1 & SD2 & & Dominance Outcome & SD1 & SD2 \\
\hline $\mathrm{CO}_{2}$ versus MET & $\mathrm{CO}_{2}$ dominates & $1 \%$ & $1 \%$ & $\mathrm{CO}_{2}$ versus MET & $\mathrm{CO}_{2}$ dominates & $1 \%$ & $1 \%$ \\
\hline $\mathrm{CO}_{2}$ versus NIT & $\mathrm{CO}_{2}$ dominates & $1 \%$ & $1 \%$ & $\mathrm{CO}_{2}$ versus NIT & $\mathrm{CO}_{2}$ dominates & $1 \%$ & $1 \%$ \\
\hline $\mathrm{CO}_{2}$ versus OTH & $\mathrm{CO}_{2}$ dominates & $1 \%$ & $1 \%$ & $\mathrm{CO}_{2}$ versus OTH & $\mathrm{CO}_{2}$ dominates & $1 \%$ & $1 \%$ \\
\hline MET versus NIT & Methane dominates & $1 \%$ & $1 \%$ & MET versus NIT & Methane dominates & $1 \%$ & $1 \%$ \\
\hline MET versus OTH & Methane dominates & $1 \%$ & $1 \%$ & MET versus OTH & Methane dominates & $1 \%$ & $1 \%$ \\
\hline NIT versus OTH & Nitrous oxide dominates & $1 \%$ & $1 \%$ & NIT versus OTH & Nitrous oxide dominates & $1 \%$ & $1 \%$ \\
\hline
\end{tabular}

$\mathrm{CO}_{2}$ represents the total $\mathrm{CO}_{2}$ emissions; MET represents the total methane emissions; NIT represents the total nitrous oxide emissions; OTH represents the total other GHG emissions. All emissions are measured in same units as thousand metric tons of $\mathrm{CO}_{2}$ equivalent emissions. First column in each panel represents the all possible sub-industry comparisons. Dominance outcome column offers the dominance outcome between sub-industry comparisons for each respective case at the years 1990, 1995, 2000 and 2005 respectively. SD1 and SD2 represent the significance levels for the first- and second-order dominance. 
Table 9

Pair-wise SD comparisons of total and sub-industry water pollution over time.

\begin{tabular}{|c|c|c|c|c|c|c|c|}
\hline \multicolumn{4}{|c|}{ a)Total water pollution } & \multicolumn{4}{|c|}{ b)Water pollution from chemistry industry } \\
\hline & & 1995 & 2000 & & & 1995 & 2000 \\
\hline \multirow[t]{2}{*}{2000} & SD1 & NA & NA & 2000 & SD1 & NA & NA \\
\hline & SD2 & NA & NA & & SD2 & $10 \%$ & NA \\
\hline \multirow[t]{2}{*}{2005} & SD1 & NA & NA & 2005 & SD1 & NA & NA \\
\hline & $\mathrm{SD} 2$ & $10 \%$ & NA & & SD2 & $10 \%$ & NA \\
\hline \multicolumn{4}{|c|}{ c)Water pollution from clay and glass industry } & \multicolumn{4}{|c|}{ d)Water pollution from food industry } \\
\hline & & 1995 & 2000 & & & 1995 & 2000 \\
\hline \multirow[t]{2}{*}{2000} & SD1 & NA & NA & 2000 & SD1 & NA & NA \\
\hline & SD2 & NA & NA & & SD2 & $10 \%$ & NA \\
\hline \multirow[t]{2}{*}{2005} & SD1 & NA & NA & 2005 & SD1 & NA & NA \\
\hline & SD2 & $10 \%$ & NA & & SD2 & $5 \%$ & NA \\
\hline \multicolumn{4}{|c|}{ e)Water pollution from metal industry } & \multicolumn{4}{|c|}{ f)Water pollution from paper and pulp industry } \\
\hline \multirow{3}{*}{2000} & & 1995 & 2000 & & & 1995 & 2000 \\
\hline & SD1 & NA & NA & 2000 & SD1 & NA & NA \\
\hline & SD2 & NA & NA & & SD2 & NA & NA \\
\hline \multirow[t]{2}{*}{2005} & SD1 & NA & NA & 2005 & SD1 & NA & NA \\
\hline & SD2 & $10 \%$ & NA & & SD2 & NA & NA \\
\hline \multicolumn{4}{|c|}{ g)Water pollution from textile industry } & \multicolumn{4}{|c|}{ h)Water pollution from wood industry } \\
\hline \multirow{3}{*}{2000} & & 1995 & 2000 & & & 1995 & 2000 \\
\hline & SD1 & NA & NA & 2000 & SD1 & NA & NA \\
\hline & SD2 & NA & NA & & SD2 & $10 \%$ & NA \\
\hline \multirow[t]{2}{*}{2005} & SD1 & NA & NA & 2005 & SD1 & NA & NA \\
\hline & SD2 & NA & NA & & SD2 & $5 \%$ & NA \\
\hline
\end{tabular}

The vertical columns represent the years 2000 and 2005 that are tested for stochastic dominance against years from 1995 and 2000. Percentage levels in the table represent the significance level of stochastic dominance. NA represents that there is no dominance at that order. 
Table 10

Pair-wise SD comparison of water pollution from industries.

\begin{tabular}{|c|c|c|c|c|c|c|c|c|c|}
\hline \multirow[b]{2}{*}{ Industry comparisons } & \multicolumn{3}{|c|}{$\begin{array}{l}\text { Water pollution sub-industry } \\
\text { comparisons in } 1995\end{array}$} & \multicolumn{3}{|c|}{$\begin{array}{l}\text { Water pollution sub-industry } \\
\text { comparisons in } 2000\end{array}$} & \multicolumn{3}{|c|}{$\begin{array}{l}\text { Water pollution sub-industry } \\
\text { comparisons in } 2005\end{array}$} \\
\hline & Dominance Outcome & SD1 & SD2 & Dominance Outcome & SD1 & SD2 & Dominance Outcome & SD1 & SD2 \\
\hline Chemical versus Clay & Chemical dominates & $10 \%$ & $5 \%$ & Chemical dominates & $10 \%$ & $5 \%$ & Chemical dominates & $5 \%$ & $5 \%$ \\
\hline Chemical versus Food & NA & NA & NA & Food dominates & $5 \%$ & $5 \%$ & Food dominates & $5 \%$ & $5 \%$ \\
\hline Chemical versus Metal & Chemical dominates & $10 \%$ & $5 \%$ & Chemical dominates & $5 \%$ & $5 \%$ & Chemical dominates & $1 \%$ & $1 \%$ \\
\hline Chemical versus Paper & NA & NA & NA & Chemical dominates & NA & NA & Chemical dominates & $10 \%$ & $10 \%$ \\
\hline Chemical versus Textile & NA & NA & NA & NA & NA & NA & NA & NA & NA \\
\hline Chemical versus Wood & Chemical dominates & $1 \%$ & $1 \%$ & Chemical dominates & $1 \%$ & $1 \%$ & Chemical dominates & $1 \%$ & $1 \%$ \\
\hline Clay versus Food & Food dominates & $1 \%$ & $1 \%$ & Food dominates & $1 \%$ & $1 \%$ & Food dominates & $1 \%$ & $1 \%$ \\
\hline Clay versus Metal & Clay dominates & $10 \%$ & $10 \%$ & Clay dominates & $10 \%$ & $10 \%$ & Clay dominates & $10 \%$ & $10 \%$ \\
\hline Clay versus Paper & NA & NA & NA & NA & NA & NA & NA & NA & NA \\
\hline Clay versus Textile & Textile dominates & $10 \%$ & $1 \%$ & Textile dominates & $5 \%$ & $1 \%$ & Textile dominates & $5 \%$ & $5 \%$ \\
\hline Clay versus Wood & NA & NA & NA & NA & NA & NA & NA & NA & NA \\
\hline Food versus Metal & Food dominates & $1 \%$ & $1 \%$ & Food dominates & $1 \%$ & $1 \%$ & Food dominates & $1 \%$ & $1 \%$ \\
\hline Food versus Paper & Food dominates & $10 \%$ & $5 \%$ & Food dominates & $1 \%$ & $1 \%$ & Food dominates & $1 \%$ & $1 \%$ \\
\hline Food versus Textile & NA & NA & NA & NA & NA & NA & Food dominates & $10 \%$ & $10 \%$ \\
\hline Food versus Wood & Food dominates & $1 \%$ & $1 \%$ & Food dominates & $1 \%$ & $1 \%$ & Food dominates & $1 \%$ & $1 \%$ \\
\hline Metal versus Paper & NA & & & Paper dominates & $10 \%$ & $10 \%$ & Paper dominates & $10 \%$ & $10 \%$ \\
\hline Metal versus Textile & Textile dominates & $1 \%$ & $1 \%$ & Textile dominates & $1 \%$ & $1 \%$ & Textile dominates & $1 \%$ & $1 \%$ \\
\hline Metal versus Wood & NA & NA & NA & NA & NA & NA & NA & NA & NA \\
\hline Paper versus Textile & Textile dominates & $10 \%$ & $5 \%$ & Textile dominates & $5 \%$ & $5 \%$ & Textile dominates & $10 \%$ & $10 \%$ \\
\hline Paper versus Wood & Paper dominates & $5 \%$ & $5 \%$ & Paper dominates & NA & $10 \%$ & Paper dominates & $10 \%$ & $10 \%$ \\
\hline Textile versus Wood & Textile dominates & $1 \%$ & $1 \%$ & Textile dominates & $1 \%$ & $1 \%$ & Textile dominates & $1 \%$ & $1 \%$ \\
\hline
\end{tabular}

First column represents the all possible sub-industry water pollution comparisons. Second to fourth panels present the dominance outcome between sub-industry comparisons for each respective case for the years 1995, 2000 and 2005 respectively. SD1 and SD2 represent the significance levels for the first- and second-order dominance. NA represents that there is no dominance at that order. 


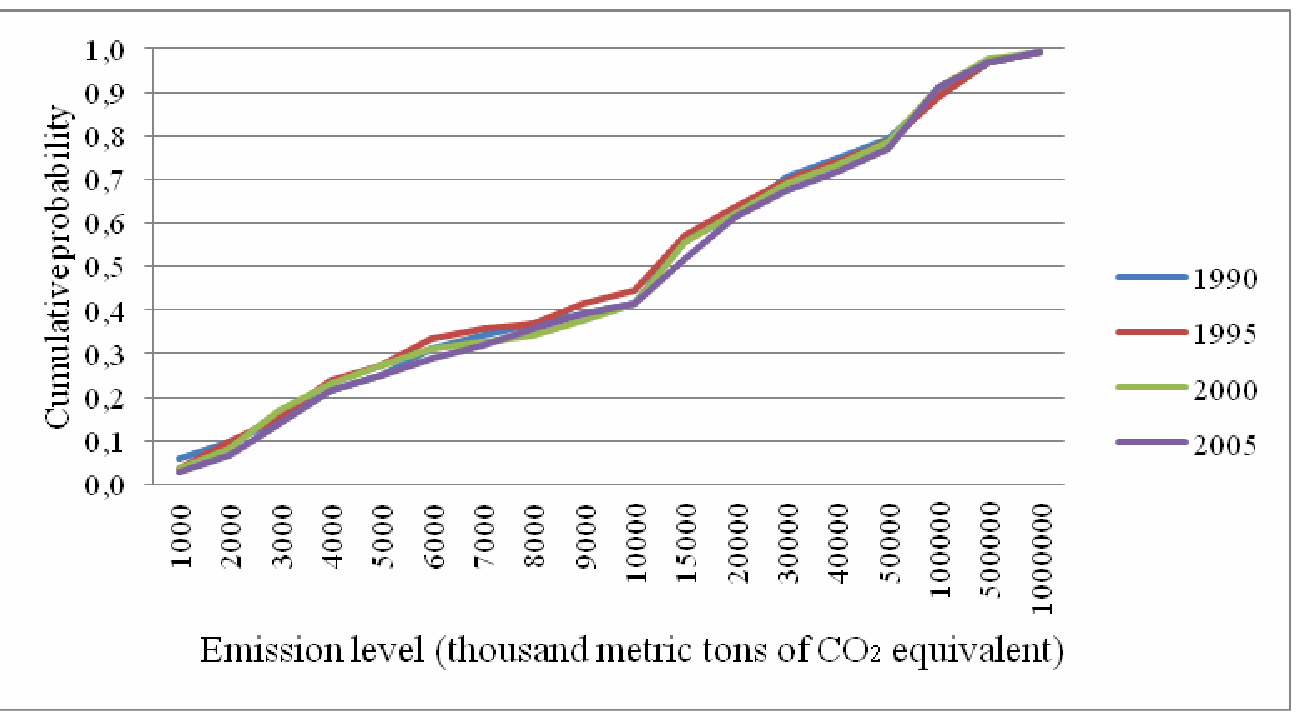

Figure 1. Cumulative distribution functions of methane emissions for 1990, 1995, 2000 and 2005

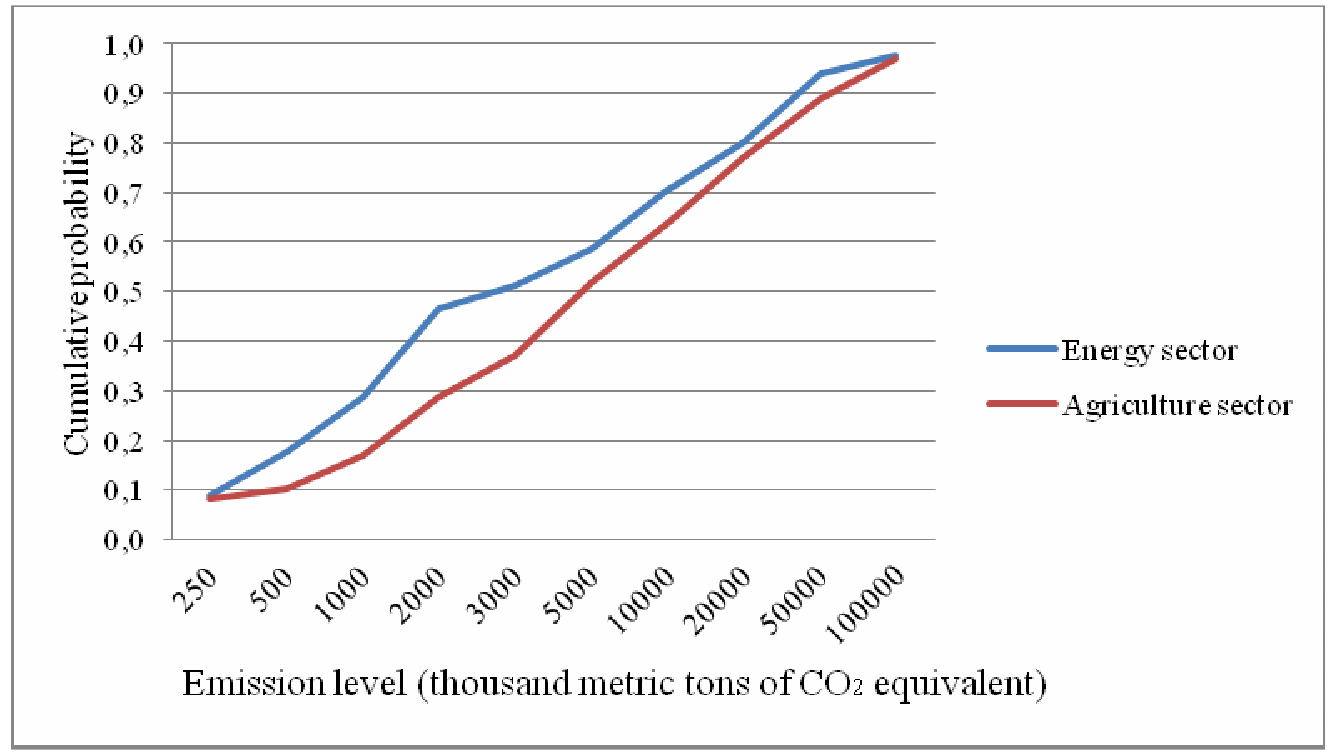

Figure 2. Cumulative distribution functions of methane emissions from agriculture and energy sector for 2005

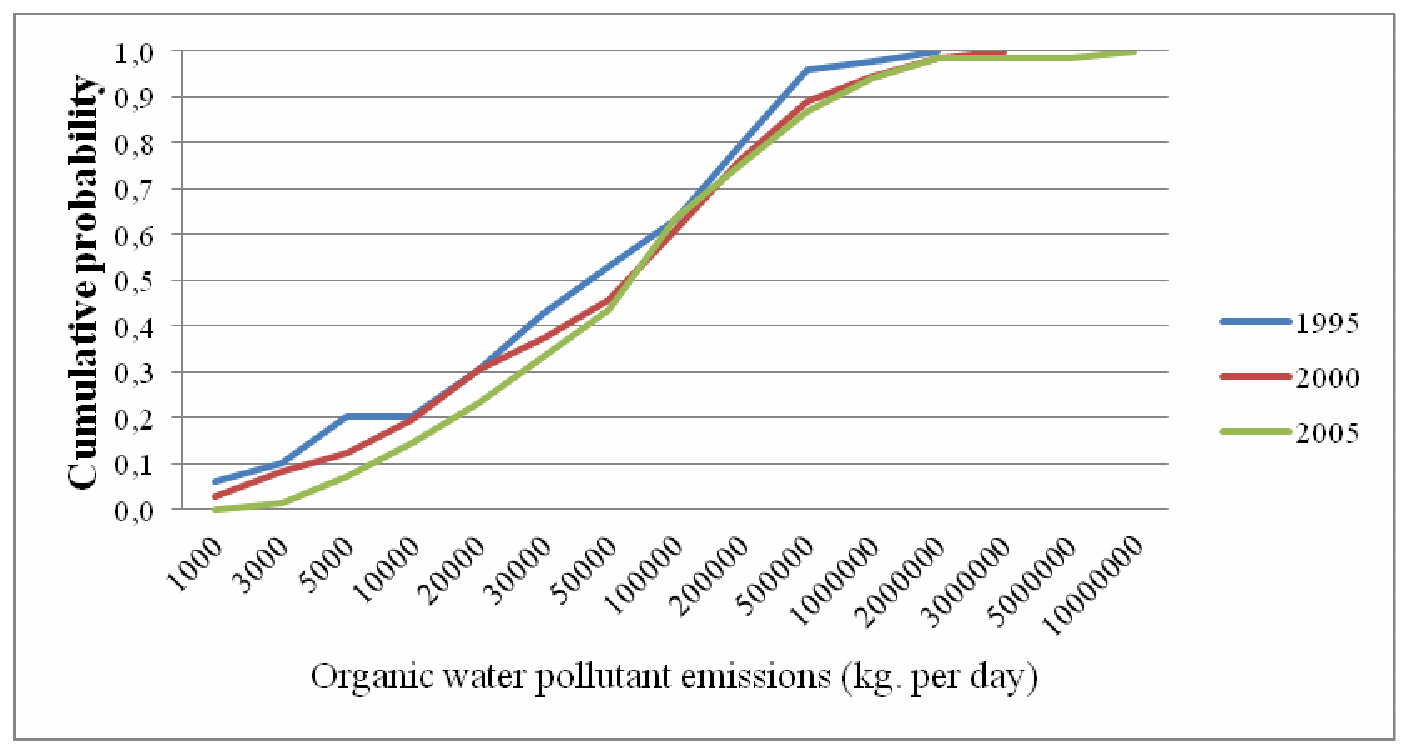

Figure 3. Cumulative distribution functions of water pollutant emissions for 1995, 2000 and 2005 


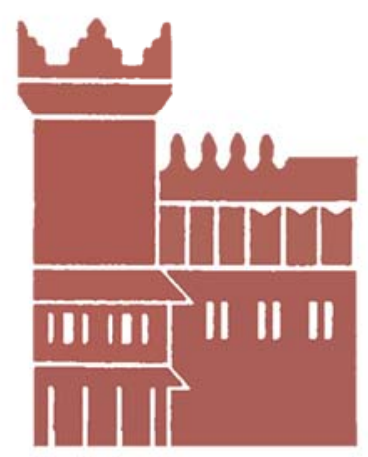

Alma Mater Studiorum - Università di Bologna DEPARTMENT OF ECONOMICS

Strada Maggiore 45

40125 Bologna - Italy

Tel. +39051 2092604

Fax +390512092664

http://www.dse.unibo.it 